\title{
NSLS VACUUM SYSTEM OPERATING EXPERIENCE CONDITIONING AND DESORPTION YIELDS*
}

\author{
Henry J. Halama \\ Brookhaven National Laboratory, NSLS - Bldg. 725C \\ Upton, N.Y. 11973
}

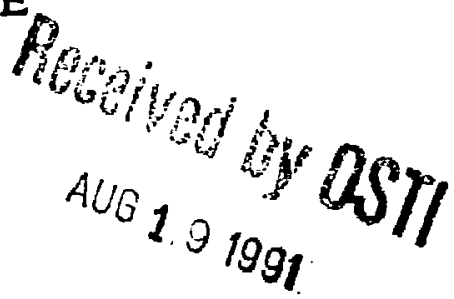

\section{ABSTRACT}

AIl stralght sections in both the VUV and the $X$-Ray rings have been filled with various insertion devices, most of them fully operational. Bean lifetime in the VUV ring is limited by the Touschek effect to - 100 minutes at $800 \mathrm{~mA}$ due to the small vertical beam size required by users. With no experiments runing, $\mathrm{X}$-Ray beam lifetime is $>35$ hours at $220 \mathrm{~mA}$ and is limited by beam gas s attaring. During the past several years the Ulo beam line was used to measure PSD yields from various metals to study their relative merits for light sources. These yields were also compared to those measured in $X$-Ray ring dipoles during inftial comissioning when desorption was high. Despice the large differences in critical photon energies, agreement was quite good. Both rings are now fully conditioned and their pressures and lifetimes have reached equilibriun. Well established conditioning procedures are followed after every incervention into their vacum systems.

\section{INTRODUCTION}

Photon stimulated desorption, PSD, is the most important factor influencing the design of a lighe source vacuum system. In conventional machines, desorbed gases are removed by an approprlately scaled pumping system close to the electron beam. In newer designs more complex chambers atcempt to channel synchrotron radiation to an absorber away from the beam. The most commonly used metals in the construction of bean ducts are aluminum, stainless steel and copper and their PSD yields are discussed in the first part of this paper. The second part deals with conditioning of the X-ray ring and comparison of the data ebtained on the $010 B$ bean Iine with those obtained in the operating $X$-ray ring. In the third part the present status of the VUV and the $X$ ray fing is given along with some comments on time-dependent lifetime improvement and conditioning.

\section{DESORPTION COEFFICIENTS -UIO BEAM LINE}

Three weter long tubes made of aluminum, stainless steel and Cu-plated stainless were exposed to white photon beam having critical energy of $500 \mathrm{eV}$ at the $\mathrm{UIOB}$ bean line. ${ }^{1}$ Desorption yields.

*Work performed under the auspices of U.S. DOE under contract DE-ACO2 - 76Ch00016.

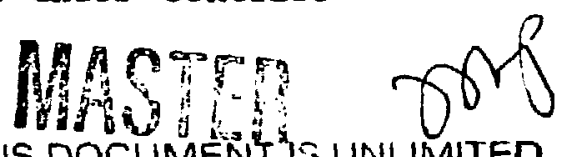


7. were measured in molecules per photon at 10 milliradian incidence and plotted versus accumulated photons. In FIg.I tubes having the following surface treatments are compax ad:

a) 6063 aluminum ${ }^{1}$ with standard Nists cleaning, ${ }^{2} 2$ day in situ $150^{\circ} \mathrm{C}$ bake-out, pressure after bake $-1 \times 10^{-9}$ TorI.

b) 304 stainless steel, ${ }^{3}$ pre-baked at $200^{\circ} \mathrm{C}$ for 2 days, back filled with dry $\mathrm{N}_{2}$, installed and pumped for about one week when $P$ - I,5 $\times 10^{-9}$ Torr was reached (no in-situ bake).

c) Cu-plated stainless, ${ }^{3}$ pre-baked at $250^{\circ} \mathrm{C}$ for 5 cays, back filled with dry $\mathrm{N}_{2}$, installed and pimped for about one week when $\mathrm{P}_{\mathrm{w}}$ $1.5 \times 10^{-5}$ Torr was reached (no in-situ bake).

Fig. 2 depicts the lowest $\eta \mathrm{s}$ obtained by glow discharge in nitrogen for $\mathrm{Al}^{3}$ and in $A I$ 108 $\mathrm{O}_{z}$ for stainless, respectively. Referring to the above figures and various other experimental data gained on the UIOB beam Iine we can make the following observation:

1) Aluminum exhibits initial yields between 20 and 1.00 times greater than stainless. The steeper slope in aluminum catches up with stainless within a dose of $-10^{24}$ photons $\mathrm{m}^{-1}$.

2) PSD yields of common gases found in vacuum systems, 1.e., $\mathrm{H}_{2}, \mathrm{CO}$ and $\mathrm{CO}_{2}$, are similar in $\mathrm{Cu}$ and stainless for comparable surface treatments.

3) After a week of pumping to a pressure $-1 \times 10^{-9}$ Torr, the water peak in an unbaked stainless eube is desorbed within $-10^{23}$ photons $\mathrm{m}^{-1}$. In a storage ring this is likely to take longer duo to reflected photons, but an in-3itu bake out may not be required.

4) A test run using only a pre-baked Al tube vas started, but had to be terminated because a very high initial $\mathrm{H}_{2} \mathrm{O}$ pressure Fise would heve required a lengthy low current operation.

In-situ bake is essential in both NSLS storage rings employing aluminum beam tubes after each exposure to the atuosphere. Otherwise, conditioning time would be prohibitively long.

5) The lowest $\eta s$ are measured on surfacos which are subjected to glow discharge cleaning.

\section{X-RAY RING DESORPTION AND CONDITIONING}

The data presented in the previous section allows us to make some predications as to how much time is $11 \mathrm{kely}$ to be required to reach reasonable beam lifetime which is governed primarily by beamgas interaction. Since Bremsstrahlung and Coulomb scattering are far more effective in degrading lifecime for $\mathrm{CO}$ and $\mathrm{CO}_{2}$ than for $\mathrm{H}_{2}$, $\mathrm{H}_{2}$ is omftted in subsequent figures. To carry out the measurements calibrated BAG and RGA were mounted on the XIBMI dipole aluminum vacuum chamber containing a $\mathrm{Cu}$ crocch through which synchrotron radiation is extracted into beam lines, and a distributed ion pump (DIP). The entire machine including front ends was baked out above $100^{\circ} \mathrm{C}$ for one week" resulting in pressure of I $\times 10^{-10}$ Torr after cool-down. Hydrogen comprised 958 of residual gases. Very large gas bursts $\left(10^{-6}\right.$ Torr) were observed during the initial stages of comissioning. After one ampere-hour the desorbed gas content 
depicted in FIg. 3 was $438 \mathrm{H}_{2}, 258 \mathrm{CO}-\mathrm{N}_{2}, 168 \mathrm{CO}$ and $16 \% \mathrm{CH}_{4} . \Delta P / I$ (pressure rise normalized to beam current in TorI/mA) is plotted racher than $n$, because neither the total pumping speed nor the Incldent photon flux are known sufficiently well. Assuming Sz 1001 $s^{-1} m^{-1}$ in the dipole $\eta_{\text {eo }}$ at $1 \times 10^{23}$ photon/m $\leq 4 \times 10^{-5}$. A rough comparison is given in Table $I$.

\section{TABLE I}

\section{UI0B X Ray Ring}

\begin{tabular}{|c|c|c|}
\hline \multicolumn{3}{|r|}{$\mathrm{Al}+\mathrm{Cu}$ crotsh } \\
\hline & $150^{\circ} \mathrm{C}, 24 \mathrm{hrs}$. & $<120^{\circ} \mathrm{C}, 5$ days \\
\hline$\epsilon_{e}:(\mathrm{eV})$ & 500 & 1700 \\
\hline & $10 \mathrm{mr}$ & 110 m \\
\hline $\begin{array}{l}\text { at } 10^{23} \text { photons } / \text { mk }^{*} \\
\text { at } 10^{24} \text { photons/m }\end{array}$ & $\begin{array}{lll}8 \times 20^{-5} \\
2 \times 10^{-5}\end{array}$ & $\begin{array}{l}<3 \times 10^{-5} \\
<1 \times 10^{-5}\end{array}$ \\
\hline
\end{tabular}

* additional $10^{23}$ photons/m at $136 \mathrm{aV}$

Despite many differences, the agreenent is quite good.

The fact that the $\mathrm{X}$-ray ring beam energy varies form .75 to $2.5 \mathrm{GeV}$ during each operating cycle permits us to measure $\Delta P / I$ s as a function of piroton energy from 126 aV to $5 \mathrm{keV}$. The data was taken several times during machine conditioning and is shown in FIgs. 4 ant 5 at $10 \mathrm{~A}$-hrs. We also note that $\Lambda P / I$ decreases by a factor of 10 and 40 for $\mathrm{CO}$ and $\mathrm{CO}_{2}$, respectively, after $600 \mathrm{~A}$-hrs at $2.5 \mathrm{GeV}$. Almost no change occurred between 400 and $600 \mathrm{~A}$-hrs. Furthezmore, the slope of the curves in Figs. 4 and 5 decreased with conditioning by $a$ factor of approximately 2 between 10 and 600 A-hrs.

\section{NSLS STORAGE RITGS}

The performance of synchrotron light sources is meacured primarily in terms of bean lifetime, beam size, and the recovery of normal operation after a section of the machine has been brought to atmospheric pressure. All the above qualities depend to a large degree on the design of the vacuum system and its flexibility. The vacuum aystems of the NSLS storage rings and their performance have been described previously. ${ }^{4-9}$ They are routinely operated ewentyfour hours a day with scheduled scudies and maintenance shifts. Following any intervention into the vacuum chamber, $\mathrm{LN}_{2}$ boll-off is used for back-fill and standard procedures are followed.2

\section{A. VUV RING}

The VUV ring operates at $750 \mathrm{MeV}\left(\epsilon_{c}-500 \mathrm{G}\right)$ and to date has accumulated over 8000 A-hours. The highest achieved beam 
current of 1200 wA was limited by machine components such as heating of cerarics and available rf power. Routinely the ring is filled with $700-900 \mathrm{~mA}$ as shown in Fig.6 The pressure in the machine bas reached equilibrium around 1500 A-hours, 1.e., subsequent running of 6000 A-hours produced no significant improvement elther in pressure or lifetime. This is due primarily to 16 beam lines which are connected directly to the machine and thus doninate its pressure changes. After the first 500 A-hours the Iffetime has been Iimited by:

1) Touschek effect which depends prinarily on electron density in the bunch and is significant in lower energy machines only: since TTay ${ }^{3}$.

2) ion trapping - where residual gas molecules ionized by circulating electrons tend to nautralize the beam and produce addition beam gas scattering.

As seen in Fig. 7, continuous improvement in pressure during the early stages permits operation with more binches which further improves both the pressure and lifetime. As the walls of the vacuun chamber are scrubbed by synchrotron radiation, the comissioning time decreases and today represents only a few Ahours after a section has been venced to $\mathrm{LN}_{2}$ boil-off.

The highest pressure, observed in bending magnets which comprise -12 of the circumference, varies linearly with beam current and reads -11 nTort at $1000 \mathrm{~mA}$. In the rest of the ring (37 m), Including the straight sections, the if cavity, insertion devices, and infectrr, the pressure at $1000 \mathrm{~mA}$ is $-2.5 \mathrm{nTorr}$. This results in total average pressure of $-4.5 \mathrm{nTorr}$ with the following partial pressures:

$\begin{array}{lllll}\mathrm{H}_{2} & (2) & - & 3 & \text { nTorr } \\ \mathrm{H}_{2} \mathrm{O} & (18) & < & 0.2 & \text { nTorr } \\ \mathrm{CO}-\mathrm{N}(28) & & 2.4 & \text { nTorr } \\ \mathrm{CO}_{2}(44) & - & 0.4 & \text { nTorr }\end{array}$

which ylelds pressure dependent lifetime $>5$ hours. However, inspection of Fig. 8 reveals a lifetime of 100 mimutes orly caused by Toushek effect. (Note the giod agreement betwenn one and six bunch operation) The reason that almost no change in lifetime is observed between 600 and $1000 \mathrm{~mA}$ is due to bunch shortening which keeps the electron density almost constant. One can obtain longer Iifetime at the expense of beam size (emittance) by increasing the horizontal-vertical coupling, as seen in Fig. 7 Curve 5/90. Unfortunately, most experiments require small vertical bean size and therefore small coupiing of - 18. Trapped lon also increase the beam size by defecusing the beam. Lifetime could be improved only by lowering electron density, 1.e., by filling all 9 available If bunches. At present the vUV ring can work with up to 7 consecutive bunches due to onset of ion trapping. Reliable operating with 8 or 9 bunches is not possible since ton clearing system ${ }^{10}$ is ineffective, probably because $\beta$ min occurs in the center of the dipoles. The only way, then, to increase the lifecime is to 
Incraase the bunch length by installing a harmonic cavity which was done last month. Testing is now in progress.

\section{X RAY RING}

The X-ray ring operares at $2.5 \mathrm{GeV}$ ( $\epsilon_{z}-5 \mathrm{keV}$ ) with four insertion devices having $\epsilon_{z}$ up to $20 \mathrm{kaV}$. The first phase of 627 Ampere-hours his been described previously in Ref. 4, 7,8 and 9 . During the ensuing shut-down major modifications to acionodate insertion devices were carrled out." We will cover orily the commissioning and the operation following this wore than ong year long shut-down. Unlike the VUV, which has full energy injection, the X-ray ring is filled at $750 \mathrm{MeV}\left(\epsilon_{5}-150 \mathrm{eV}\right)$ and the stacked beam is then accelerated to $2.5 \mathrm{GeV}$. This fact makes the condftioning significancly more time consuming. The first 28 Ahours are shown in Fig. 9, excluding running at lower energy during stacking and acceleration. After 16 A-hours lifetime at 100 ait exceeded 5 hours and the beam became usable for experiments. At 75 A-hours including minor intervientions into the vacuum system, I $X$ $\tau$ product rezched 2000. Since Touschek effect is negligible due to $2.5 \mathrm{GeV}$ energy, lifecime is determined entirely by beam-gas scattering and is inversely proportional to pressure.

The ring ( $170 \mathrm{~m}$ in circumference) is divided into sections according to the gas load. The pressures read on callbrated gauges and averaged over respectso sections are cabulated in Iable II.

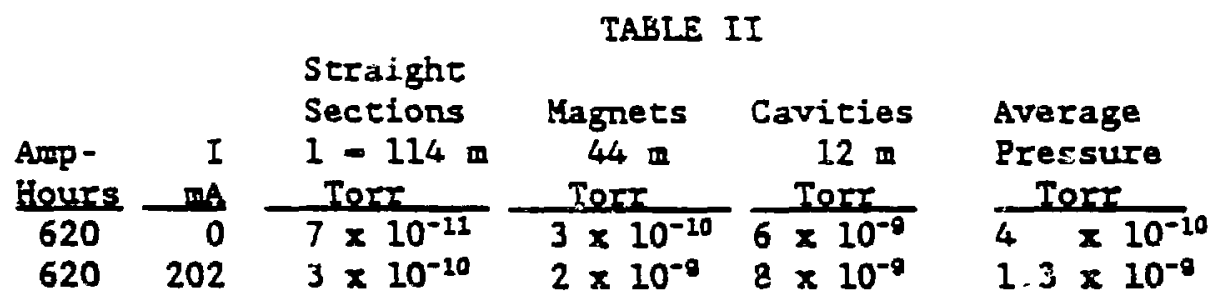

$\begin{array}{rrrrrrrr}1200 & 0 & 5 \times 10^{-11} & <2 \times 10^{-10} & 4 \times 10^{-10} & 1 \times 10^{-10} \\ 1200 & 230 & 1.7 \times 10^{-10} & 1.1 \times 10^{-9} & 1.5 \times 10^{-9} & 5 \times 10^{-10}\end{array}$

After 600 A-hours the residual gas content at high current operation is $618 \mathrm{H}_{2}, 348 \mathrm{CO}$ and $58 \mathrm{CO}_{2}$. In Table III we list calculated $r_{c}$ and measured $r_{\text {a }}$ lifetimes along with $\Delta P / I$ s averaged over the entire machine. Desorption in the dipoles is significantly higher. 
TABLE III

\begin{tabular}{|c|c|c|c|c|c|}
\hline $\begin{array}{l}\text { Amp - } \\
\text { Houts }\end{array}$ & $\begin{array}{l}I \\
m A\end{array}$ & $\begin{array}{l}\Delta P / I \\
\text { Torr/ma }\end{array}$ & $\begin{array}{l}\text { Pressure } \\
\text { Tor } \\
\end{array}$ & $\begin{array}{c}r_{v} \\
\text { Hours }\end{array}$ & $\begin{array}{l}r_{E} \\
\text { Hours }\end{array}$ \\
\hline $\begin{array}{c}1 * \\
10 \star \\
620 \star \\
+1200\end{array}$ & $\begin{array}{l}50 \\
50 \\
200 \\
230\end{array}$ & $\begin{array}{l}5 \times 10^{-10} \\
2.5 \times 10^{-10} \\
6.4 \times 10^{-12} \\
2.2 \times 10^{-12}\end{array}$ & $\begin{array}{lll}1.3 \times 10^{-9} \\
5 \times 10^{-10}\end{array}$ & $\begin{array}{l}-0.5 \\
-1 \\
8 \\
37\end{array}$ & 43 \\
\hline
\end{tabular}

*Before 1987 shut-down

The machine commissioning was started in April, 1989 and the A-hour clock was reset to zero. The lifetime at $200 \mathrm{~mA}$ in $\mathrm{Fig} .10$ shows a five fold increase which is tue to the following:

1) Increase in dynamic apperture.

2) decrease in gas desorption from the walls due to synchrotron radiation scrubbing (Table II).

3) increase in if power.

4) improvement in RF cavity pressu-e and performance due to new Helcoflex seals and titanium nitrading.

5) Installation of new plate DIPs ${ }^{13}$ and NEG modules.

6) improvement in DIP pumping sperd after long operation in good vacuums.

The shaded strip (1990 in Fig. 10) gives the Iifetimes with all Insertion devices operating and $4 \mathrm{I}$ field on the wiggler magnet. When the IEGS (Laser-Electron-Gamin-ray Spectroscopy) beam Iine is open the lifetime is halved. Further degradation in Iifetime is observed when the wiggler field is raised to $4.7 \mathrm{I}$. The best lifetime ( $B$ in $F_{B}$. 10) is obtained with LEGS and insertion devices not operaclonal and the wiggler field set to zero T. Fig. 11 shows typical "good" operation winen one fill (250-110 $\mathrm{mA}$ ) lasts more than twenty-four hours.

\section{DISCLAIMER}

This report was prepared as an account of work sponsored by an agency of the United States Government. Neither the United States Government nor any agency thereof. nor any of their employees. makes any warranty, express or implied, or assumes any legal liability or responsibility for the accuracy, completeness, or usefulness of any information, apparatus, product, or process disclosed, nt represents that its use would not infringe privately owned rights. Reference herein to any specific commercial product. process, or service by trade name, trademark, manufacturer, or otherwise does not necessarily constitute or imply its endorsement, recom. mendation, or favoring by the United States Government or any agency thereof. The views and opinions of authors expressed herein do not necessarily state or reflect those of the United States Government or any agency thereof. 


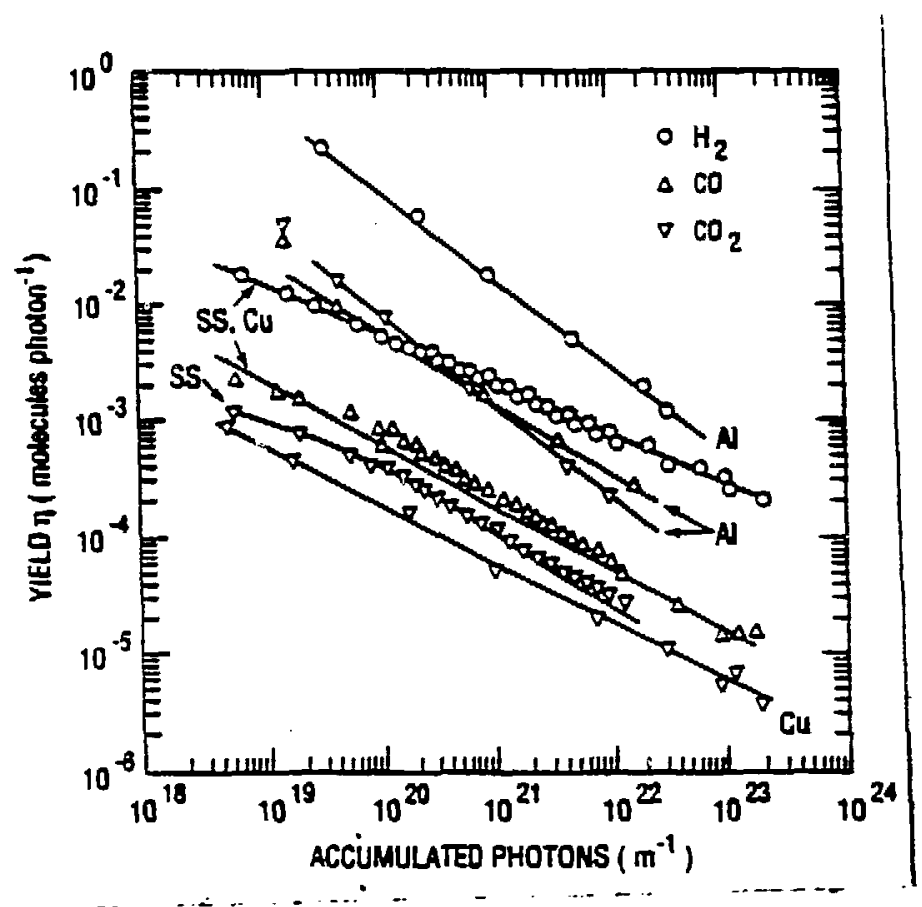

FIg. 1 Comparison of desorption yields from baked alumimum, prebaked stainless and pre-baked copper-plated stainless

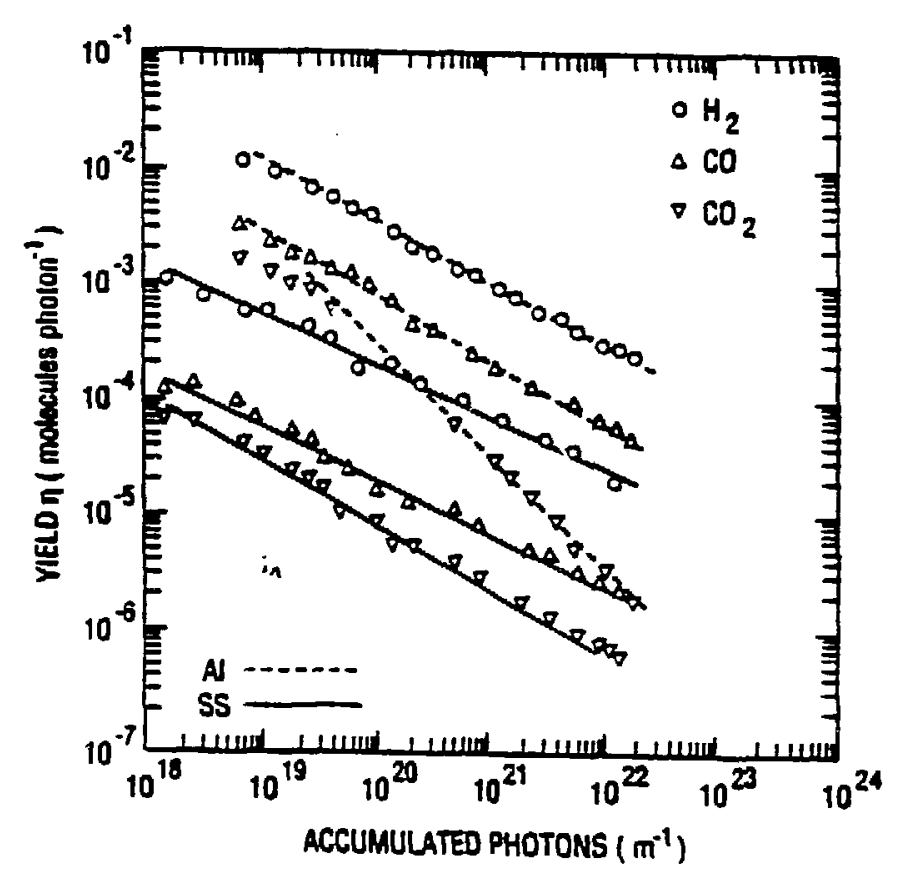

Fig. 2 Comparison of desorption yields fron glow discharged aluminum and stainless steel 


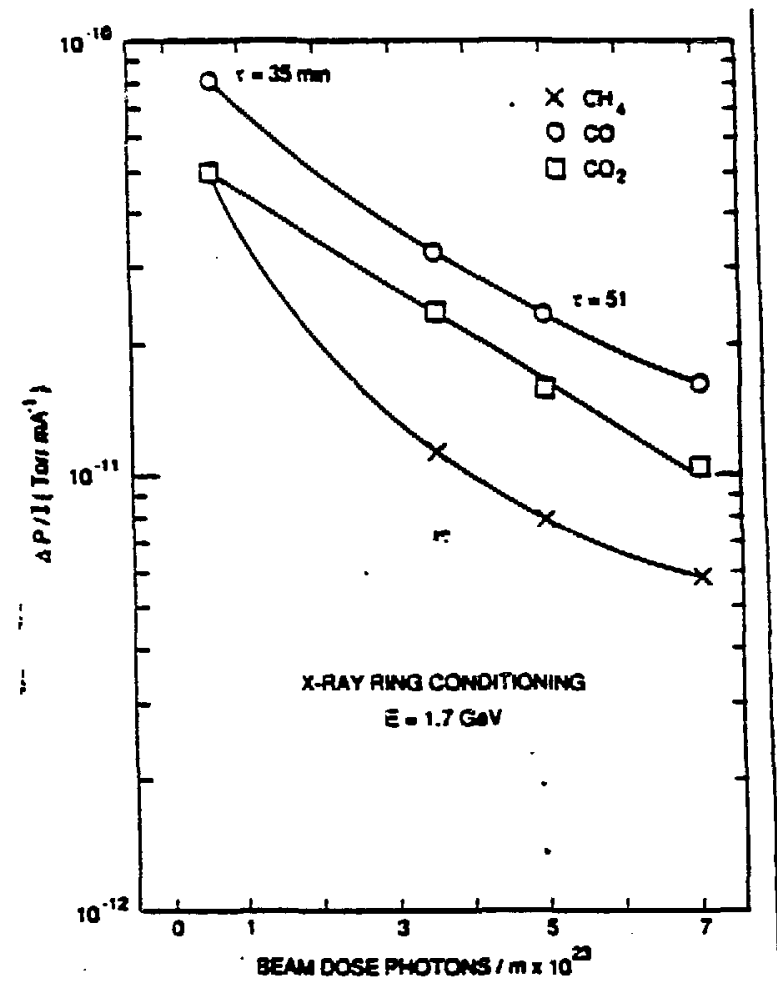

Fig. 3 Normalized partial pressure rise, $\Delta P / I$, in $X-R a y$ dipoles during first 7 A-hours of conditioning.

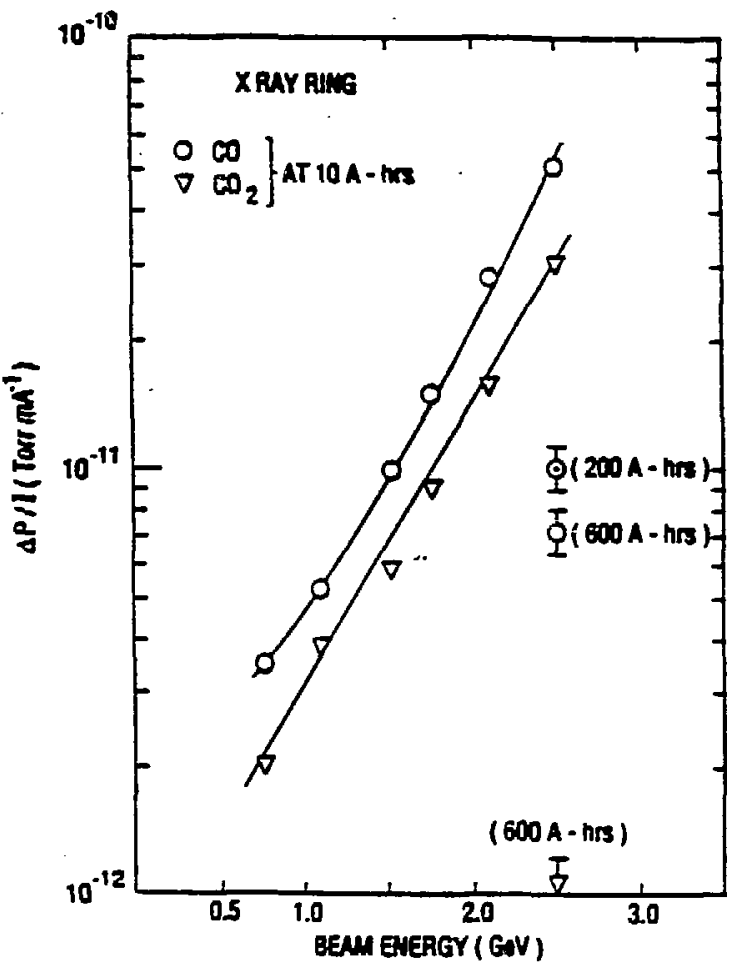

FIg. 4 Normalized partlal pressure rise, $\Delta / P I$, in $X-R a y$ dipoles vs bean energy (IA-hour $=1 \times 10^{23}$ photons/m) 


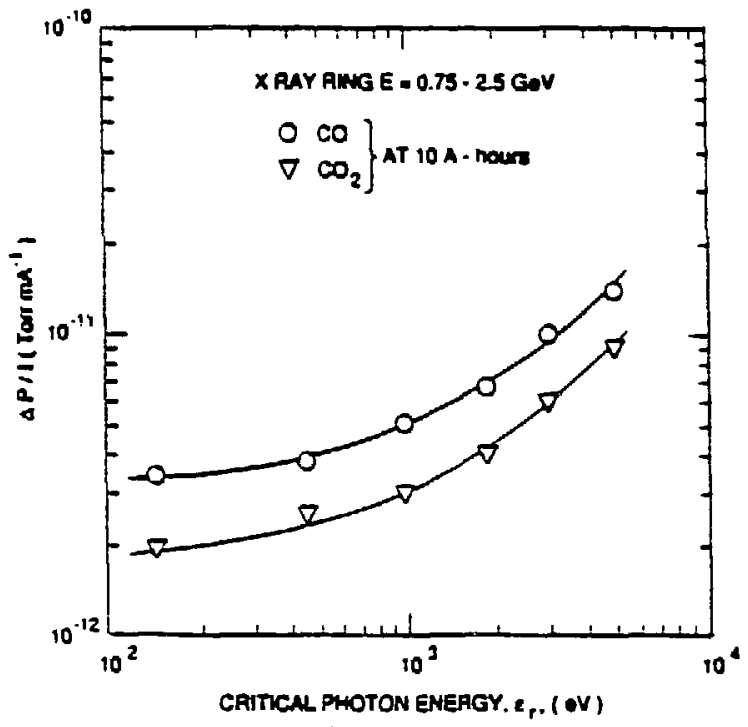

FIg. $5 \Delta P / I$ in $X$-Ray ring dipoles vs critical photon energy

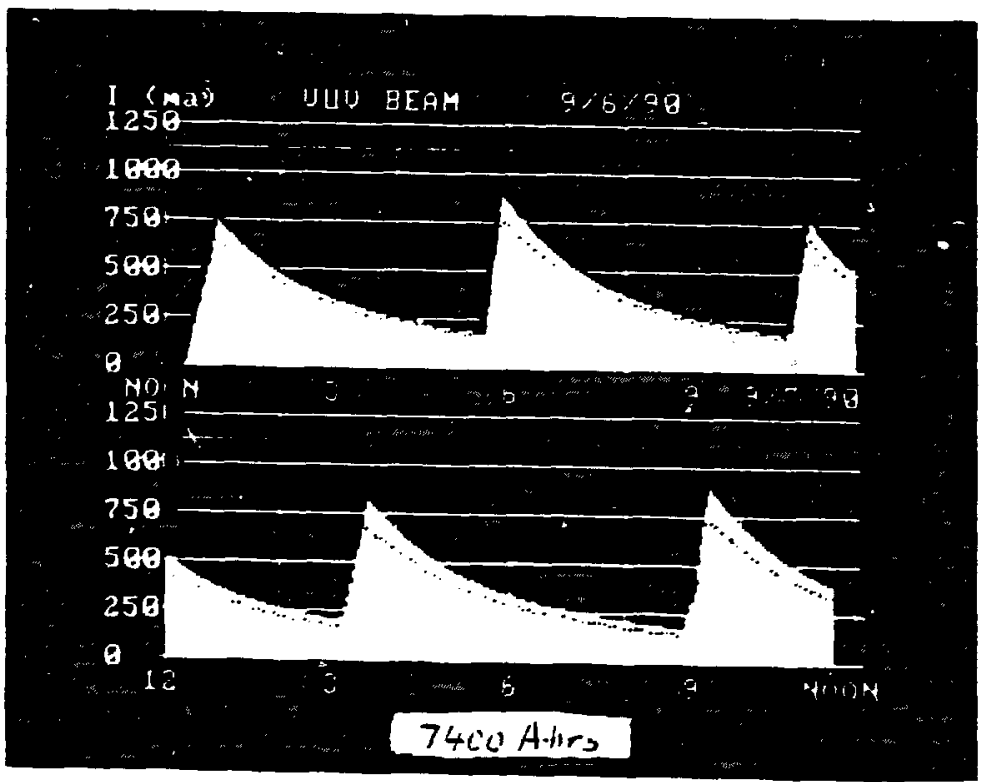

Fig. 6 VWV ring beam current and pressure variations during 25 hours of typical operation 


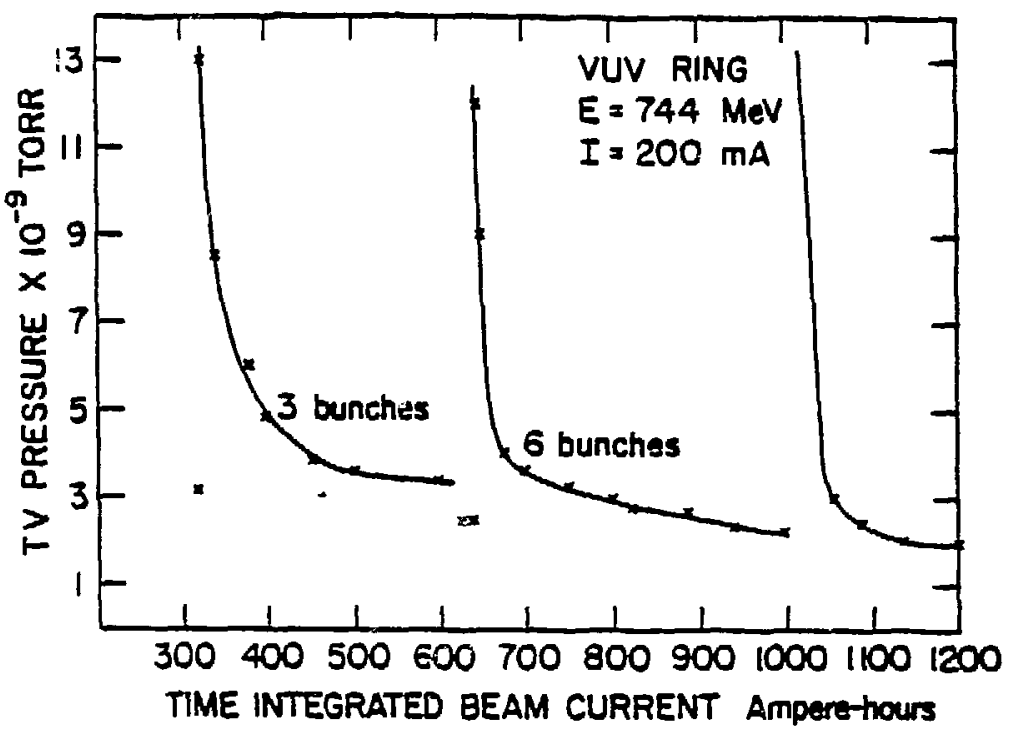

Eig. 7 VUV pressure changes vs time due to venting of the vacuum chamber during the first 1200 A-hours

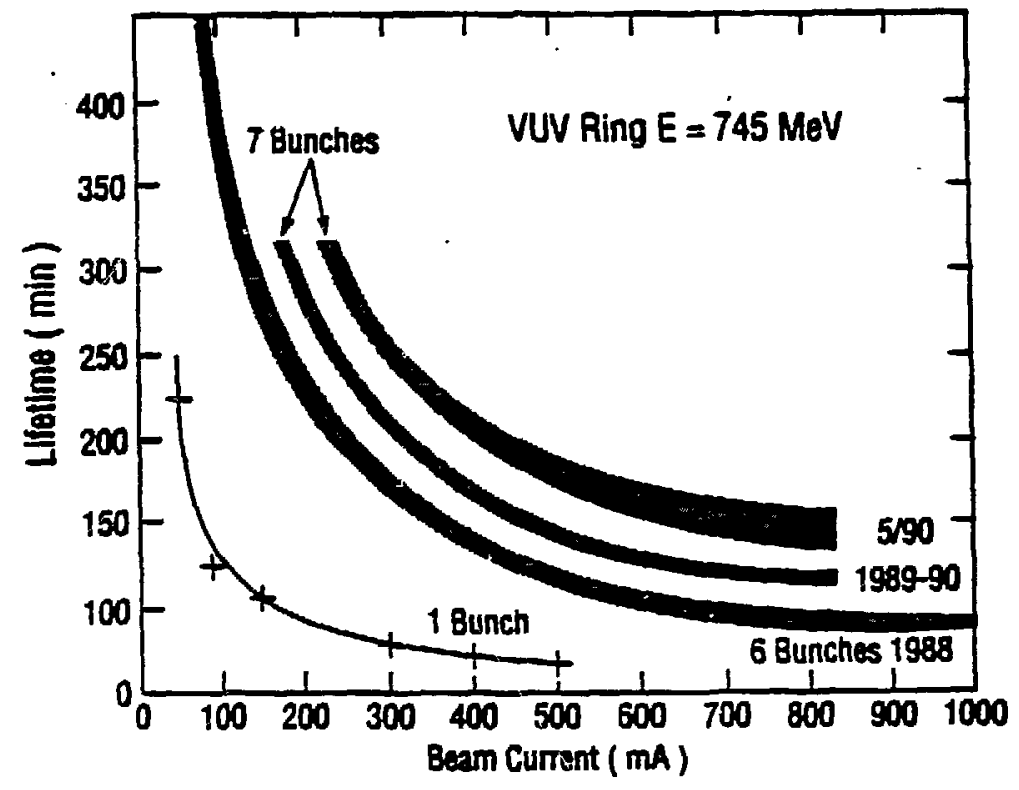

Fig. 8 VUV ring measured bean lifetime vs beam current for several bunch modes 

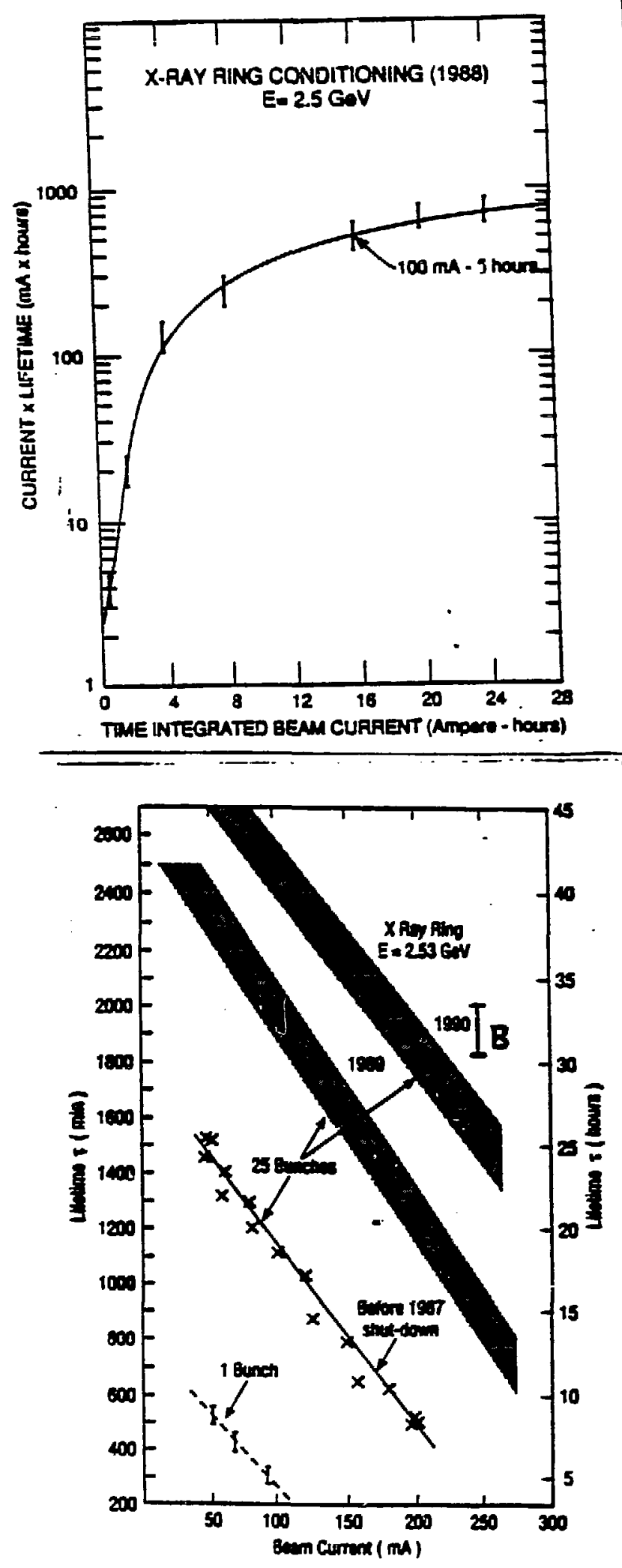

Fig. 9 CurrentLifetine product during the firse 28 A-hours of conditioning
Fig. $10 \cdots$-Ray ring measured lifetime vs beam currene during a four year span 


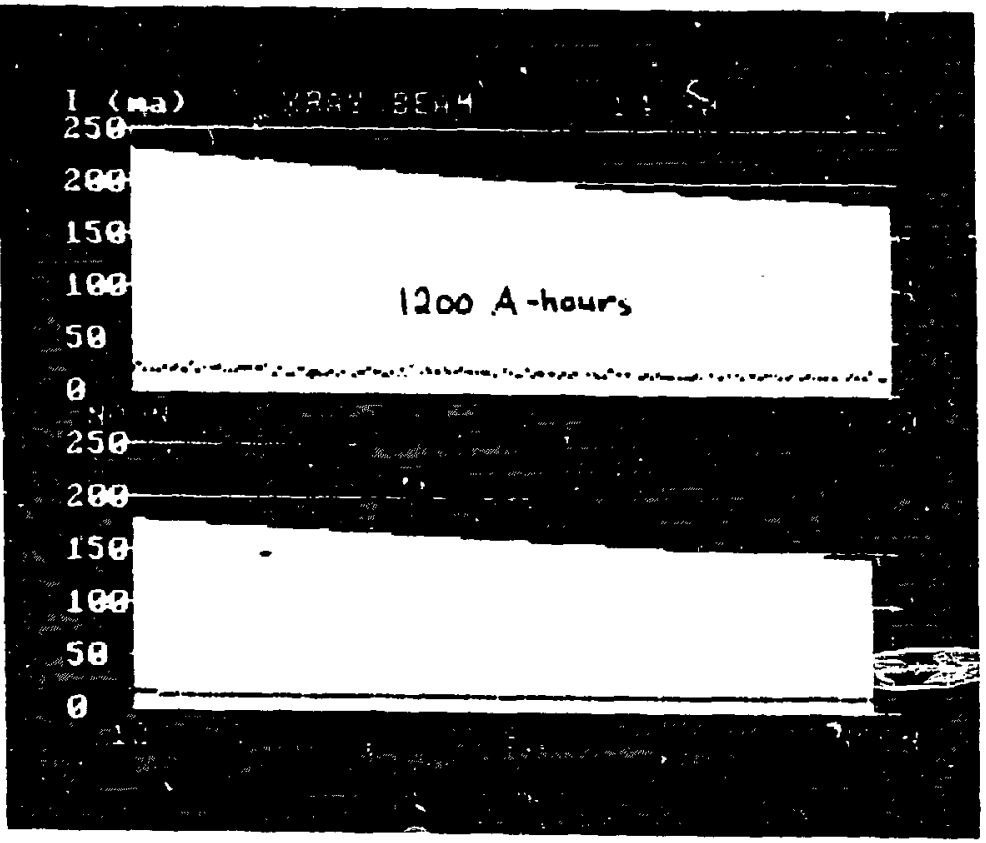

Fig. Il X-Ray Iing beam and pressure behavior during 24 hours of typical operation.

\section{REFERENCES}

1. T. Kobari and H.J. Halama, J. Vac. Sci. Technol. A5(4), 2355 (1987).

2. H. J. Halama, AIP Conference Proceedings No 199, 93 (1989).

3. C. L. Foerster, H. J. Halama and C. Lanni, J. Vac. Sei. Tachnol. A8 (3), 2856 (1990).

4. H. J. Halann, J. Vac. SeI. Technol. A3, 1699 (1985).

5. J. C. Schuchman ot al., J. Vac. Sc1. Technol. 16, 720 (1979).

6. J. C. Schuchman, J. Vac. Sci. Technol. Al, 196 (1983).

7. H. J. Halama, C. I. Foerster and T. Kobari, J. Vac. Sc1. Technol., AS (4), 2342 (1987).

8. H. J. Halama, BNL Report No. BNL 39768 (1987).

9. H. J. Halama, AIP Conference Proceedings No. 171, 227 (1988).

10. I. S. Chou and H. J. Halama, Proc. 1987 IEEE Pareiclo Accelerator Conference, 1773 (1987).

11. T. S. Chou, J. Vac. Sci. Technol. 5 (6), 3446 (1987). 